\title{
Longitudinal Assessments of Erythropoietin- Stimulating Agent Responsiveness and the Association with Specific Clinical Outcomes in Dialysis Patients
}

\author{
Andreas Schneider ${ }^{\mathrm{a}} \quad$ Lena Gutjahr-Lengsfeld ${ }^{\mathrm{a}} \quad$ Eberhard Ritz ${ }^{\mathrm{C}}$ \\ Hubert Scharnagl $^{d}$ Götz Gelbrich ${ }^{b}$ Stefan Pilz ${ }^{\mathrm{e}}$ lain C. Macdougall ${ }^{f}$ \\ Christoph Wanner ${ }^{\mathrm{a}}$ Christiane Drechsler $^{\mathrm{a}}$ \\ ${ }^{a}$ Division of Nephrology, Department of Medicine, University Hospital Würzburg, and ${ }^{\mathrm{b}}$ Institute of Clinical \\ Epidemiology and Biometry, University of Würzburg, Würzburg, and ${ }^{C}$ Division of Nephrology, Department of \\ Internal Medicine, University of Heidelberg, Heidelberg, Germany; ${ }^{d}$ Clinical Institute of Medical and \\ Chemical Laboratory Diagnostics, and e Division of Endocrinology and Metabolism, Department of Internal \\ Medicine, Medical University of Graz, Graz, Austria; ${ }^{f}$ Renal Unit, King's College Hospital, London, UK
}

\section{Key Words}

Dialysis · Erythropoietin · Diabetes · Epidemiology

\begin{abstract}
Background: Dose requirements of erythropoietin-stimulating agents (ESAs) can vary considerably over time and may be associated with cardiovascular outcomes. We aimed to longitudinally assess ESA responsiveness over time and to investigate its association with specific clinical end points in a time-dependent approach. Methods: The German Diabetes and Dialysis study (4D study) included 1,255 diabetic dialysis patients, of whom 1,161 were receiving ESA treatment. In those patients, the erythropoietin resistance index (ERI) was assessed every 6 months during a median follow-up of 4 years. The association between the ERI and cardiovascular end points was analyzed by time-
\end{abstract}

dependent Cox regression analyses with repeated ERI measures. Results: Patients had a mean age of $66 \pm 8.2$ years; $53 \%$ were male. During follow-up, a total of 495 patients died, of whom 136 died of sudden death and 102 of infectious death. The adjusted and time-dependent risk for sudden death was increased by $19 \%$ per 5 -unit increase in the $\mathrm{ERI}$ (hazard ratio, $\mathrm{HR}=1.19,95 \%$ confidence interval, $\mathrm{Cl}=$ 1.07-1.33). Similarly, mortality increased by $25 \%(H R=1.25$, $95 \% \mathrm{Cl}=1.18-1.32$ ) and infectious death increased by $27 \%$ $(\mathrm{HR}=1.27,95 \% \mathrm{Cl}=1.13-1.42)$. Further analysis revealed that lower 25-hydroxyvitamin D levels were associated with lower ESA responsiveness $(p=0.046)$. Conclusions: In diabetic dialysis patients, we observed that time-varying erythropoietin resistance is associated with sudden death, infectious complications and all-cause mortality. Low 25-hydroxyvitamin D levels may contribute to a lower ESA responsiveness.

\section{KARGER}

E-Mail karger@karger.com www.karger.com/nec
(C) 2014 S. Karger AG, Basel

$1660-2110 / 14 / 1282-0147 \$ 39.50 / 0$ 


\section{Introduction}

Recently, there has been intense discussion on the safety of erythropoietin treatment in patients with chronic kidney disease (CKD). Specifically, resistance to erythropoietin-stimulating agents (ESAs) has been associated with increased mortality. A cross-sectional study based on 94,569 prevalent hemodialysis patients found that ESA dose requirement was an independent predictor of all-cause death [1]. A similar conclusion was reached in the secondary analysis of the CHOIR study, where highdose ESA usage was significantly associated with cardiovascular events [2].

In particular, the TREAT study in type 2 diabetic patients with CKD found significantly higher rates of stroke and cardiac revascularization procedures in ESA nonresponders [3]. In recent years, it has become increasingly apparent that death in advanced CKD is often due to sudden cardiac death, which accounts for a quarter of all deaths in dialysis patients. Apart from cardiac comorbidities, vitamin D deficiency and other suspected contributing factors, ESA resistance may play a particular role. No data exist, however, about the impact of ESA responsiveness on the occurrence of sudden cardiac death.

Importantly, ESA doses may vary considerably over time. Longitudinal changes in hemoglobin concentration in dialysis patients have been reported, potentially leading to dose adjustments in ESA use $[4,5]$. This, in turn, points to the need to evaluate longitudinal assessments of ESA requirements in the association with specific clinical events.

This prompted us to investigate the association of time-varying ESA responsiveness with sudden death and other cardiovascular outcomes in dialysis patients using a time-dependent approach. We used data from the German Diabetes and Dialysis study (4D study) [6], which consists of a well-defined cohort of 1,255 type 2 diabetic patients undergoing hemodialysis treatment.

\section{Methods}

\section{Design of the 4D Study}

The $4 \mathrm{D}$ study design, main outcome findings and baseline data have been described previously [6]. In short, the $4 \mathrm{D}$ study was a prospective randomized controlled trial recruiting 1,255 hemodialysis patients with type 2 diabetes mellitus aged $18-80$ years from 178 German dialysis centers. Eligible patients were randomly assigned to receive either $20 \mathrm{mg}$ of atorvastatin daily or matching placebo. The mean length of follow-up was 4.0 years. The primary end point of the $4 \mathrm{D}$ study was defined as a composite of death from cardiac causes, stroke and myocardial infarction (MI). Death from cardiac causes comprised fatal MI (death within 28 days after a diagnosis of $\mathrm{MI}$ ), sudden death, death due to congestive heart failure, death due to coronary heart disease during or within 28 days after an intervention, and all other deaths ascribed to coronary heart disease. Patients who died unexpectedly and did not present with a potassium level $<7.5 \mathrm{mmol} / \mathrm{l}$ before the start of the three most recent sessions of hemodialysis were considered to have had sudden death from cardiac causes. All events were reviewed and adjudicated by a critical end point committee blinded to treatment allocation [6]. For the present analysis, sudden cardiac death, MI, stroke, the combined cardiovascular end point (CVE), all-cause death, heart failure death, and infectious death were chosen to be separate outcome measures and were based on the primary judgment of the end point committee during the $4 \mathrm{D}$ study.

The study adhered to the International Conference on Harmonization guidelines for Good Clinical Practice and was conducted in accordance with the Declaration of Helsinki. The protocol was approved by the Ethics Committee at the University of Würzburg. All participants provided written informed consent.

\section{Data Collection}

Information on demographic characteristics such as age and smoking status were obtained through patient interviews. Comorbidities including the presence of coronary artery disease and congestive heart failure, as well as the duration of diabetes mellitus and dialysis treatment, were reported by the patients' nephrologists. Blood pressure was measured in a sitting position. Body mass index was calculated as weight (kilograms) divided by height (meters squared). Data on hemoglobin (grams/deciliter) and ESA dose (IU/kilogram/week) were collected every 6 months. From these values we calculated the erythropoietin resistance index (ERI; weekly weight-adjusted ESA dose/hemoglobin). The median ERI measurement was $4(2-7)$, with a minimum of 1 and a maximum of 11 .

\section{Vitamin D Measurements}

Levels of 25-hydroxyvitamin D [25(OH)D] were measured in serum samples taken at baseline and stored without repeated freeze-thaw cycles at $-80^{\circ} \mathrm{C}$. Determinations in serum were performed by means of a chemiluminescence assay: IDS-iSYS 25(OH)D (Immunodiagnostic Systems Ltd., Boldon, UK) on an IDS-iSYS multidiscipline automated analyzer. Within-day and inter-day coefficients of variation were $5.5-12.1 \%$ and $8.9-16.9 \%$, respectively. All blood samples were taken before the start of dialysis sessions and administration of drugs.

\section{Statistical Analyses}

Continuous variables were expressed as the mean with standard deviation (SD) or median with interquartile range, as appropriate. Categorical variables were expressed as percentages. We performed a time-dependent Cox regression analysis to take into account ERI as a time-varying risk factor on the prespecified outcomes. For that purpose, we used the last observation carried forward' method to minimize the number of missing ERI values. ERI was considered as a continuous variable, which was measured every 6 months.

Furthermore, we investigated visit-to-visit ERI variability (i.e. standard deviation of the ERI calculated according to the available ERI values from all visits of each individual) on single end points. 
All analyses were adjusted for the confounders age, sex, allocation to atorvastatin or placebo and $25(\mathrm{OH}) \mathrm{D}$.

In additional analyses, we investigated the association between ERI and vitamin D status. Therefore, we formed four groups according to their $25(\mathrm{OH}) \mathrm{D}$ status at baseline. In line with widely used cut-off values, the patients were grouped as follows: (1) severely vitamin $\mathrm{D}$ deficient $(\leq 25 \mathrm{nmol} / \mathrm{l}),(2)$ moderately vitamin $\mathrm{D}$ deficient ( $>25$ and $\leq 50 \mathrm{nmol} / \mathrm{l})$, (3) vitamin D borderline ( $>50$ and $\leq 75 \mathrm{nmol} / \mathrm{l}$ ) and (4) vitamin D sufficient (>75 nmol/l; to convert nanomolars to nanograms per milliliter, divide by 2.496 ).

We used ANOVA to compare ERI values across vitamin D categories. Patients with sufficient 25(OH)D levels were used as the reference group.

All $\mathrm{p}$ values reported are two-sided, and a $\mathrm{p}$ value $<0.05$ was considered statistically significant.

\section{Results}

\section{Patient Characteristics}

Altogether, 1,255 patients were included in the $4 \mathrm{D}$ study. The mean follow-up period was 4.0 years for the atorvastatin group (median $=4.0$ years) and 3.9 years for those on placebo (median $=4.08$ years). A total of $92.5 \%$ of the patients $(\mathrm{n}=1,161)$ received erythropoietin and had a hemoglobin measurement to calculate the ERI. During follow-up, 495 patients died; 136 of these died of sudden cardiac death. A total of 376 patients had CVEs, with MI and stroke occurring in 153 and 86 patients, respectively. Furthermore, 102 patients died because of infections and 32 died due to congestive heart failure.

In the final study population $(\mathrm{n}=1,161)$, the mean age was $66 \pm 8.2$ years; $53 \%$ of the patients were male. The mean baseline hemoglobin level was $10.9 \pm 1.3 \mathrm{~g} / \mathrm{dl}$, with no significant difference between the atorvastatin and placebo groups. The mean level of $25(\mathrm{OH}) \mathrm{D}$ at baseline was $45.2 \pm 24.7 \mathrm{nmol} / \mathrm{l}$. Baseline characteristics of the patients are shown in table 1.

\section{Erythropoietin Resistance Status and Risk of Specific}

Clinical Outcomes in a Time-Dependent Approach

In a time-dependent Cox regression analysis, ERI status was significantly associated with sudden death. The adjusted risk of sudden death increased by 19\% (hazard ratio, $\mathrm{HR}=1.19,95 \%$ confidence interval, $\mathrm{CI}=1.07-1.33$ ) per 5-unit increase in the ERI. Similarly, mortality was higher by $25 \%(\mathrm{HR}=1.25,95 \% \mathrm{CI}=1.18-1.32)$ per 5 -unit increase in the ERI.

Furthermore, erythropoietin resistance status was strongly associated with infectious death in a time-dependent approach. The adjusted risk for infectious death was $27 \%$ higher $(\mathrm{HR}=1.27,95 \% \mathrm{CI}=1.13-1.42)$ per increase of 5 units in
Table 1. Patient characteristics

\begin{tabular}{|c|c|c|}
\hline Characteristics & $\begin{array}{l}\text { Patients } \\
\text { without any ERI } \\
(\mathrm{n}=94)\end{array}$ & $\begin{array}{l}\text { Patients with } \\
\text { at least } 1 \text { ERI } \\
(\mathrm{n}=1,164)\end{array}$ \\
\hline Age, years & $66.0 \pm 8.9$ & $65.7 \pm 8.2$ \\
\hline Male gender, $\%$ & 67 & 53 \\
\hline Systolic BP, mm Hg & $143.0 \pm 17.1$ & $146 \pm 22$ \\
\hline Diastolic BP, mm Hg & $77.8 \pm 10.2$ & $75.7 \pm 11.0$ \\
\hline BMI & $27.6 \pm 4.7$ & $27.5 \pm 4.8$ \\
\hline Duration of diabetes, years & $18.8 \pm 10.1$ & $18.1 \pm 8.7$ \\
\hline Time on dialysis, months & $9.1 \pm 7.2$ & $8.2 \pm 6.9$ \\
\hline Arteriovenous fistula, \% & 76.6 & 84.2 \\
\hline \multicolumn{3}{|l|}{ History of disease, $\%$} \\
\hline CAD & 25.5 & 20.8 \\
\hline $\mathrm{CHF}$ & 47.9 & 34.4 \\
\hline PVD & 44.7 & 44.6 \\
\hline Smoker or ex-smoker, \% & 46.8 & 39.9 \\
\hline ACE inhibitor use, $\%$ & 29.8 & 49.4 \\
\hline \multicolumn{3}{|l|}{ Laboratory parameters } \\
\hline LDL cholesterol, mg/dl & $131 \pm 32$ & $125 \pm 30$ \\
\hline Hemoglobin, g/dl & $11.5 \pm 1.4$ & $10.9 \pm 1.3$ \\
\hline Ferritin, $\mu \mathrm{g} / \mathrm{l}$ & $396 \pm 347$ & $494 \pm 431$ \\
\hline Transferrin, $\mu \mathrm{g} / \mathrm{l}$ & $2.1 \pm 0.4$ & $1.9 \pm 0.4$ \\
\hline Iron saturation, $\%$ & $10.9 \pm 4.6$ & $10.3 \pm 4.6$ \\
\hline Albumin, g/dl & $3.9 \pm 0.2$ & $3.8 \pm 0.3$ \\
\hline $\begin{array}{l}\text { Parathyroid hormone, } \\
\qquad \mathrm{pg} / \mathrm{ml}\end{array}$ & $131 \pm 139$ & $100 \pm 117$ \\
\hline C-reactive protein, $\mathrm{mg} / \mathrm{l}$ & $5.3(2.6-10.5)$ & $5.0(2.3-12.5)$ \\
\hline Calcium, $\mathrm{mmol} / \mathrm{l}$ & $2.3 \pm 0.2$ & $2.3 \pm 0.2$ \\
\hline Phosphate, mg/dl & $5.8 \pm 1.7$ & $6.1 \pm 1.6$ \\
\hline $\mathrm{HbA}_{1 \mathrm{c}}, \%$ & $7.1 \pm 1.3$ & $6.7 \pm 1.3$ \\
\hline 25(OH)D3, nmol/l & $16.2 \pm 8.0$ & $18.1 \pm 9.9$ \\
\hline
\end{tabular}

Values are presented as means $\pm S D$, median with interquartile range or percentages, as appropriate. $\mathrm{BP}=$ Blood pressure; $\mathrm{BMI}=$ body mass index; $\mathrm{CAD}=$ coronary artery disease $\mathrm{CHF}=$ conges tive heart failure; $\mathrm{PVD}=$ peripheral vascular disease $\mathrm{LDL}=$ lowdensity lipoprotein; $\mathrm{HbA}_{1 \mathrm{c}}=$ glycosylated hemoglobin.

the ERI. There was also a higher risk of stroke, CVE and death due to heart failure by an increase in the ERI.

In contrast, erythropoietin resistance status was not significantly associated with $\mathrm{MI}$ in a time-dependent approach (table 2).

Visit-to-Visit Variability in Erythropoietin Resistance and the Risk of Adverse Clinical Outcome

After adjustment for potential confounders, we found ERI variability to be independently associated with mortality $(\mathrm{HR}=1.07,95 \% \mathrm{CI}=1.03-1.10 ; \mathrm{p}<0.001)$, fatal infections $(\mathrm{HR}=1.09,95 \% \mathrm{CI}=1.02-1.17 ; \mathrm{p}=0.007)$ and 
Table 2. Erythropoietin resistance status and risk of specific clinical outcomes in a time-dependent approach

\begin{tabular}{|c|c|c|}
\hline Outcome & HR per 5 units of ERI & $\mathrm{p}$ value \\
\hline \multicolumn{3}{|l|}{ Sudden death } \\
\hline Crude & $1.20(1.08-1.33)$ & $<0.001$ \\
\hline Adjusted $^{1}$ & $1.18(1.06-1.31)$ & 0.0019 \\
\hline Adjusted $^{2}$ & $1.18(1.06-1.31)$ & 0.0020 \\
\hline Adjusted $^{3}$ & $1.19(1.07-1.33)$ & 0.0019 \\
\hline \multicolumn{3}{|l|}{ Mortality } \\
\hline Crude & $1.25(1.19-1.31)$ & $<0.001$ \\
\hline Adjusted $^{1}$ & $1.24(1.18-1.30)$ & $<0.001$ \\
\hline Adjusted $^{2}$ & $1.24(1.18-1.30)$ & $<0.001$ \\
\hline Adjusted $^{3}$ & $1.25(1.18-1.32)$ & $<0.001$ \\
\hline \multicolumn{3}{|c|}{ Infectious death } \\
\hline Crude & $1.27(1.15-1.40)$ & $<0.001$ \\
\hline Adjusted $^{1}$ & $1.27(1.15-1.41)$ & $<0.001$ \\
\hline Adjusted $^{2}$ & $1.27(1.15-1.41)$ & $<0.001$ \\
\hline Adjusted $^{3}$ & $1.27(1.13-1.42)$ & $<0.001$ \\
\hline \multicolumn{3}{|c|}{ Heart failure death } \\
\hline Crude & $1.21(0.99-1.49)$ & 0.06 \\
\hline Adjusted $^{1}$ & $1.25(1.02-1.54)$ & 0.03 \\
\hline Adjusted $^{2}$ & $1.25(1.01-1.54)$ & 0.04 \\
\hline Adjusted $^{3}$ & $1.29(1.04-1.60)$ & 0.02 \\
\hline \multicolumn{3}{|l|}{ MI } \\
\hline Crude & $1.04(0.92-1.16)$ & 0.56 \\
\hline Adjusted $^{1}$ & $1.04(0.92-1.17)$ & 0.56 \\
\hline Adjusted $^{2}$ & $1.03(0.92-1.16)$ & 0.59 \\
\hline Adjusted $^{3}$ & $1.01(0.99-1.04)$ & 0.37 \\
\hline \multicolumn{3}{|l|}{ Stroke } \\
\hline Crude & $1.16(1.01-1.33)$ & 0.04 \\
\hline Adjusted $^{1}$ & $1.11(0.97-1.28)$ & 0.13 \\
\hline Adjusted $^{2}$ & $1.12(0.97-1.28)$ & 0.13 \\
\hline Adjusted ${ }^{3}$ & $1.16(1.01-1.34)$ & 0.04 \\
\hline \multicolumn{3}{|l|}{ CVE } \\
\hline Crude & $1.12(1.05-1.20)$ & 0.001 \\
\hline Adjusted $^{1}$ & $1.11(1.04-1.19)$ & 0.003 \\
\hline Adjusted $^{2}$ & $1.11(1.04-1.19)$ & 0.003 \\
\hline Adjusted $^{3}$ & $1.14(1.06-1.23)$ & $<0.001$ \\
\hline
\end{tabular}

Values in parentheses are $95 \%$ CI.

${ }^{1}$ Model 1: adjusted for age and sex.

${ }^{2}$ Model 2: additional adjustment for atorvastatin.

${ }^{3}$ Model 3: additional adjustment for 25(OH)D.

death due to heart failure $(\mathrm{HR}=1.13,95 \% \mathrm{CI}=1.01-1.26$; $\mathrm{p}=0.04)$. Furthermore, there was a borderline significant trend with cardiovascular events $(\mathrm{HR}=1.03,95 \% \mathrm{CI}=$ 0.99-1.08; $\mathrm{p}=0.09$ ).

\section{Association of Vitamin D Status with Erythropoietin \\ Resistance}

Patients with lower 25(OH)D levels $(<25 \mathrm{nmol} / \mathrm{l})$ had higher ESA doses and a higher ERI compared with the

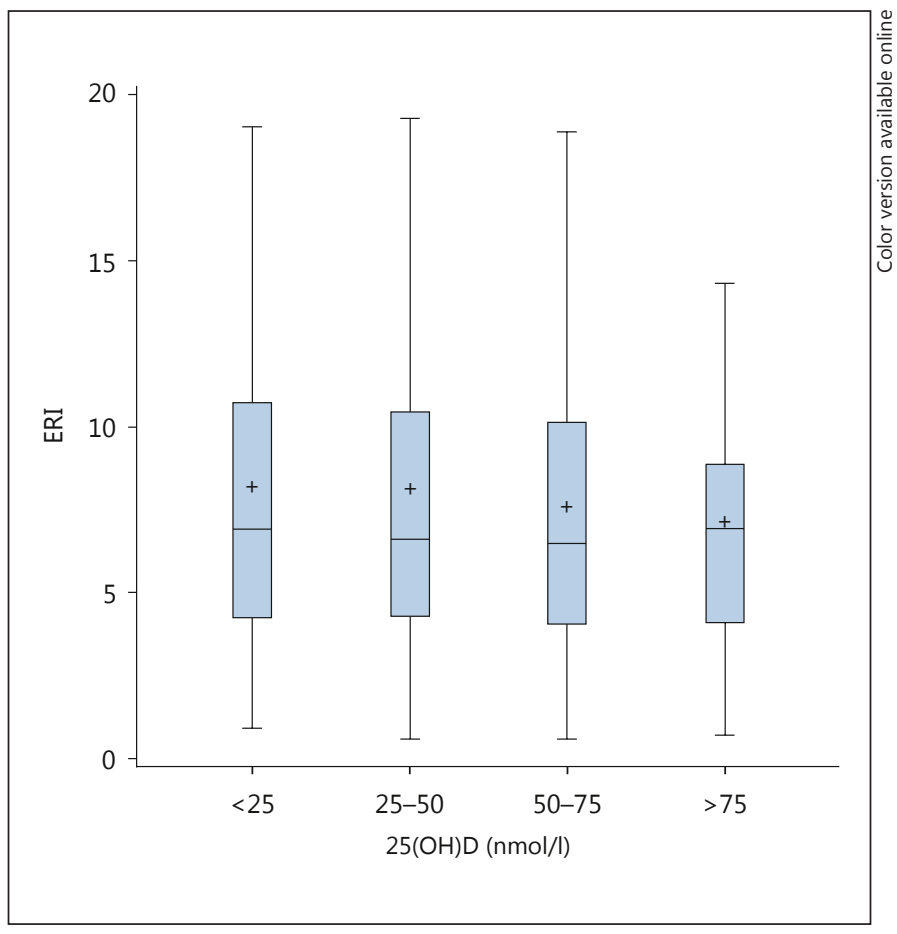

Fig. 1. Association between baseline serum $25(\mathrm{OH}) \mathrm{D}$ concentration and mean ERI level. $\mathrm{p}=0.046$ : $\mathrm{p}$ value refers to the comparison of the lowest vs. the highest vitamin D quartile.

patients with normal 25(OH)D levels ( $>75 \mathrm{nmol} / \mathrm{l} ; \mathrm{p}=$ $0.046)$. The mean level of ESA dose in patients without $25(\mathrm{OH}) \mathrm{D}$ deficiency was $75 \pm 40.53 \mathrm{IU} / \mathrm{kg} /$ week. In comparison, patients with severe $25(\mathrm{OH}) \mathrm{D}$ deficiency required a mean ESA dose of $85 \pm 57.6 \mathrm{IU} / \mathrm{kg} /$ week. Accordingly, the mean values for the ERI were $7.1 \pm 4.1$ for $25(\mathrm{OH}) \mathrm{D}$-sufficient patients and $8.1 \pm 5.8$ for severely 25(OH)D-deficient patients (fig. 1).

\section{Discussion}

In the present study we found that the longitudinal assessment of ESA hyporesponsiveness was an independent risk factor for mortality, sudden death, stroke, death due to heart failure, combined cardiovascular events, and death due to infection in diabetic hemodialysis patients. Furthermore, ESA hyporesponsiveness was also associated with lower 25(OH)D levels.

With regard to all-cause mortality, our data confirm the principal observation of the TREAT study [7] in diabetic patients with advanced CKD (not requiring renal replacement therapy). Our study is, to the best of our 
knowledge, the first to highlight the role of ESA resistance and specific cardiovascular events in a time-dependent approach. There is a notable exception in the above correlations between ESA resistance and cardiovascular events, i.e. the absence of a correlation between ESA resistance with MI. The negative finding in MI patients is less surprising in view of previous animal experiments and clinical observations. ESA was even found to be cardioprotective in an animal model of MI [8], including an MI model in rats with impaired renal function [9]. Moreover, in human observations ESA attenuated the ST elevation in patients with MI, as reported by Ozawa et al. [10]. Our finding linking ESA resistance to sudden death, stroke, death due to heart failure, and CVE is in line with previously reported studies [7, $11,12]$. Our study extends the previous findings because we used a time-dependent approach. In our time-dependent analyses, ESA requirements were regularly assessed every 6 months and followed by observation periods between the respective measurements. Therefore, our results mainly represent short-term effects considering potential variability between visits. In this context, we prepared additional analyses investigating visit-tovisit ERI variability on single end points. We found ERI variability independently associated with mortality, fatal infections and death due to heart failure. Furthermore, there was a borderline significant association with cardiovascular events.

How can one further explain the relation between ESA resistance and specific clinical outcomes observed in the present analysis? An important issue is whether ESA resistance is causally linked to cardiovascular events, and which role the correlation with markers of inflammation plays in this setting. In the present study, ESA hyporesponsiveness was associated with an increased risk of infectious death. This finding is new, yet in line with several studies showing that an increased inflammation status is associated with ESA resistance [13-17]. Furthermore, in an observational study, Abe et al. [18] have demonstrated that diabetic hemodialysis patients with malnutrition inflammation syndrome have a lower response to ESA treatment. In addition, the joint occurrence of malnutrition and inflammation in hemodialysis patients is consistent with protein energy wasting [19], which is also associated with sudden cardiac death in these patients [20].

Observations potentially pointing to a causal role of inflammation in sudden death come from case-control studies in individuals with sudden death [21] and survivors of ventricular fibrillation [22]. Mechanisms involved include the development of premature atherosclerosis and cytokine-induced plaque instability [23] or direct effects of inflammation on the myocardium and electrical conduction system [24]. Cytokines are also involved in the modulation of ion channel function and the generation of arrhythmias [25, 26], as well as in the aggravation of sympathetic tone, leading to tachycardia and cardiac electrical instability.

In the present study, lower 25(OH)D levels were associated with ESA resistance in 893 patients, thus confirming the results from a small single-center study [27]. Our findings are also consistent with an observational study from Goicoechea et al. [28], showing a reduction in ESA usage and an improvement in hemoglobin values by oral vitamin D supplementation. Notably, the effects found by Goicoechea et al. [28] were independent of parathyroid hormone levels. It is thought that in CKD patients vitamin $\mathrm{D}$ deficiency might stimulate immune cells to produce cytokines. Cytokines, on the other hand, cause functional iron deficiency due to the activation of the reticuloendothelial system. They further lead to increased hepcidin synthesis [29], with the consequences of an impaired ESA response and anemia. In summary, it is tempting to speculate that vitamin $\mathrm{D}$ administration could beneficially affect ESA resistance. Prospective and randomized controlled studies are needed to prove this hypothesis.

The repeated visits with the assessment of ESA and hemoglobin status enabling a time-dependent analysis were the major strengths of this study. Further important strengths include the stringent characterization of the cohort and of the specific clinical outcomes which were analyzed. In this context, the long-term follow-up, adequate sample size and high incidence of prespecified and centrally adjudicated end points are also relevant. The major limitation of this study was that it was a post hoc analysis; furthermore, it was conducted in a selected cohort of German patients with type 2 diabetes mellitus on hemodialysis and, therefore, the findings may not be generalizable to other patient populations.

In conclusion, time-varying ESA treatment at higher doses was a strong risk factor for sudden death, stroke, death due to heart failure, combined cardiovascular events, mortality, and death due to infection. Furthermore, ESA hyporesponsiveness was increased in patients with a low vitamin D status. The regular assessment and monitoring of ESA requirement may be beneficial in the prevention of sudden death and infectious complications in dialysis patients. 


\section{Acknowledgments}

We thank all patients who participated in the $4 \mathrm{D}$ study. We are grateful to all investigators, study nurses and collaborators involved in patient recruitment and sample and data handling, and to the laboratory staff at the Universities of Freiburg, Würzburg and Graz.

\section{Disclosure Statement}

The authors have no conflicts of interest to declare.

\section{References}

1 Zhang Y, Thamer M, Stefanik K, Kaufman J, Cotter DJ: Epoetin requirements predict mortality in hemodialysis patients. Am J Kidney Dis 2004;44:866-876.

-2 Szczech LA, Barnhart HX, Inrig JK, Reddan DN, Sapp S, Califf RM, Patel UD, Singh AK: Secondary analysis of the CHOIR trial epoetin- $\alpha$ dose and achieved hemoglobin outcomes. Kidney Int 2008;74:791-798.

$\checkmark 3$ Pfeffer MA, Burdmann EA, Chen CY, Cooper ME, de Zeeuw D, Eckardt KU, Feyzi JM, Ivanovich $\mathrm{P}$, Kewalramani R, Levey AS, Lewis EF, McGill JB, McMurray JJ, Parfrey P, Parving HH, Remuzzi G, Singh AK, Solomon SD, Toto R: A trial of darbepoetin alfa in type 2 diabetes and chronic kidney disease. N Engl J Med 2009;361:2019-2032.

4 Fishbane S, Berns JS: Hemoglobin cycling in hemodialysis patients treated with recombinant human erythropoietin. Kidney Int 2005; 68:1337-1343.

5 Lacson E Jr, Ofsthun N, Lazarus JM: Effect of variability in anemia management on hemoglobin outcomes in ESRD. Am J Kidney Dis 2003;41:111-124.

6 6 Wanner C, Krane V, Marz W, Olschewski M, Mann JF, Ruf G, Ritz E: Atorvastatin in patients with type 2 diabetes mellitus undergoing hemodialysis. N Engl J Med 2005;353: 238-248.

7 Solomon SD, Uno H, Lewis EF, Eckardt KU, Lin J, Burdmann EA, de Zeeuw D, Ivanovich P, Levey AS, Parfrey P, Remuzzi G, Singh AK, Toto R, Huang F, Rossert J, McMurray JJ, Pfeffer MA: Erythropoietic response and outcomes in kidney disease and type 2 diabetes. N Engl J Med 2010;363:1146-1155.

-8 Parsa CJ, Matsumoto A, Kim J, Riel RU, Pascal LS, Walton GB, Thompson RB, Petrofski JA, Annex BH, Stamler JS, Koch WJ: A novel protective effect of erythropoietin in the infarcted heart. J Clin Invest 2003;112:9991007.

-9 Dikow R, Kihm LP, Zeier M, Kapitza J, Tornig J, Amann K, Tiefenbacher C, Ritz E: Increased infarct size in uremic rats: reduced ischemia tolerance? J Am Soc Nephrol 2004; 15:15301536.

10 Ozawa T, Toba K, Suzuki H, Kato K, Iso Y, Akutsu Y, Kobayashi Y, Takeyama Y, Kobayashi N, Yoshimura N, Akazawa K, Aizawa Y: Single-dose intravenous administration of recombinant human erythropoietin is a promising treatment for patients with acute myocardial infarction - randomized con- trolled pilot trial of EPO/AMI-1 study. Circ J 2010;74:1415-1423.

11 Koulouridis I, Alfayez M, Trikalinos TA, Balk EM, Jaber BL: Dose of erythropoiesis-stimulating agents and adverse outcomes in CKD: a metaregression analysis. Am J Kidney Dis 2013;61:44-56.

12 Panichi V, Rosati A, Bigazzi R, Paoletti S, Mantuano E, Beati S, Marchetti V, Bernabini G, Grazi G, Rizza GM, Migliori M, Giusti R, Lippi A, Casani A, Barsotti G, Tetta C: Anaemia and resistance to erythropoiesis-stimulating agents as prognostic factors in haemodialysis patients: results from the RISCAVID study. Nephrol Dial Transplant 2011;26: 2641-2648.

13 Goicoechea M, Martin J, de Sequera P, Quiroga JA, Ortiz A, Carreno V, Caramelo C: Role of cytokines in the response to erythropoietin in hemodialysis patients. Kidney Int 1998;54: 1337-1343.

14 Nassar GM, Fishbane S, Ayus JC: Occult infection of old nonfunctioning arteriovenous grafts: a novel cause of erythropoietin resistance and chronic inflammation in hemodialysis patients. Kidney Int Suppl 2002;80:4954.

15 Roberts TL, Obrador GT, St Peter WL, Pereira BJ, Collins AJ: Relationship among catheter insertions, vascular access infections, and anemia management in hemodialysis patients. Kidney Int 2004;66:2429-2436.

16 Barany P, Divino Filho JC, Bergstrom J: High $\mathrm{C}$-reactive protein is a strong predictor of resistance to erythropoietin in hemodialysis patients. Am J Kidney Dis 1997;29:565-568.

-17 Gunnell J, Yeun JY, Depner TA, Kaysen GA: Acute-phase response predicts erythropoietin resistance in hemodialysis and peritoneal dialysis patients. Am J Kidney Dis 1999;33:6372.

18 Abe M, Okada K, Maruyama T, Maruyama N, Matsumoto K, Soma M: Relationship between erythropoietin responsiveness, insulin resistance, and malnutrition-inflammationatherosclerosis (MIA) syndrome in hemodialysis patients with diabetes. Int J Artif Organs 2011;34:16-25.

19 Kopple JD: Pathophysiology of protein-energy wasting in chronic renal failure. J Nutr 1999;129:247S-251S.

20 Drechsler C, Grootendorst DC, Pilz S, Tomaschitz A, Krane V, Dekker F, Marz W, Ritz E, Wanner C: Wasting and sudden cardiac death in hemodialysis patients: a post hoc analysis of 4D (die Deutsche Diabetes Dialyse Studie). Am J Kidney Dis 2011;58:599-607.

21 Empana JP, Jouven X, Canoui-Poitrine F, Luc G, Tafflet M, Haas B, Arveiler D, Ferrieres J, Ruidavets JB, Montaye M, Yarnell J, Morange P, Kee F, Evans A, Amouyel P, Ducimetiere P: C-reactive protein, interleukin 6 , fibrinogen and risk of sudden death in European middleaged men: the PRIME study. Arterioscler Thromb Vasc Biol 2010;30:2047-2052.

22 Elmas E, Holzer L, Lang S, Popp T, Kalsch T, Wolpert C, Brueckmann M, Borggrefe M: Enhanced proinflammatory response of mononuclear cells to in vitro LPS-challenge in patients with ventricular fibrillation in the setting of acute myocardial infarction. Cytokine 2008;43:138-142.

23 Ridker PM, Buring JE, Shih J, Matias M, Hennekens $\mathrm{CH}$ : Prospective study of $\mathrm{C}$-reactive protein and the risk of future cardiovascular events among apparently healthy women. Circulation 1998;98:731-733.

24 Dernellis J, Panaretou M: C-reactive protein and paroxysmal atrial fibrillation: evidence of the implication of an inflammatory process in paroxysmal atrial fibrillation. Acta Cardiol 2001;56:375-380.

25 Hoffman BF, Feinmark SJ, Guo SD: Electrophysiologic effects of interactions between activated canine neutrophils and cardiac myocytes. J Cardiovasc Electrophysiol 1997;8: 679-687.

26 Hoffman BF, Guo SD, Feinmark SJ: Arrhythmias caused by platelet activating factor. J Cardiovasc Electrophysiol 1996;7:120-133.

27 Kiss Z, Ambrus C, Almasi C, Berta K, Deak G, Horonyi P, Kiss I, Lakatos P, Marton A, Molnar MZ, Nemeth Z, Szabo A, Mucsi I: Serum $25(\mathrm{OH})$-cholecalciferol concentration is associated with hemoglobin level and erythropoietin resistance in patients on maintenance hemodialysis. Nephron Clin Pract 2011; 117:c373-c378.

28 Goicoechea M, Vazquez MI, Ruiz MA, Gomez-Campdera F, Perez-Garcia R, Valderrabano F: Intravenous calcitriol improves anaemia and reduces the need for erythropoietin in haemodialysis patients. Nephron 1998;78: 23-27.

29 Icardi A, Paoletti E, De Nicola L, Mazzaferro S, Russo R, Cozzolino M: Renal anaemia and EPO hyporesponsiveness associated with vitamin $\mathrm{D}$ deficiency: the potential role of inflammation. Nephrol Dial Transplant 2013; 28:1672-1679. 